\title{
Peran Pemerintah Kabupaten Dharmasraya dalam Memperbaiki Kerusakan Lahan Bekas Tambang Ronaldo Juneri ${ }^{1}$, Adil Mubarak ${ }^{2}$ \\ 1,2 Universitas Negeri Padang \\ Email: ronaldojuneri51@ gmail.com, adilmubarak08@yahoo.co.id
}

\begin{abstract}
Abstrak
Pencemaran dan kerusakan lingkungan hidup semakin marak terjadi di Indonesia.Salah satu bentuk pencemaran dan kerusakan lingkungan hidup adalah lahan bekas tambang. Lahan bekas tambang merupakan lahan kritis yang tidak subur dan harus segera diperbaiki. Kabupaten Dharmasraya mempunyai lahan kritis seluas 4.144 hektar.Peran dan upaya pemerintah Kabupaten Dharmasraya sangat diperlukan untuk perbaikan lahan bekas tambang. Pasal 3 huruf e Peraturan Daerah Kabupaten Dharmasraya Nomor 10 Tahun 2012 Tentang Rencana Tata Ruang Wilayah (RTRW) Kabupaten Dharmasraya Tahun 2011-2031 menyebutkan bahwa pengembangan potensi pertambangan kabupaten dengan tetap mempertahankan kualitas lingkungan. Penelitian ini bertujuan untuk mengetahui upaya dan kendala pemerintah Kabupaten Dharmasraya dalam memperbaiki kerusakan lahan bekas tambang.Penelitian ini menggunakan metode kualitatif deskriptif.Teknik informan menggunakan purposive sampling.Teknik pengumpulan data wawancara, observasi lapangan dan studi dokumentasi.Berdasarkan hasil penelitian, perbaikan lahan bekas tambang di Kabupaten Dharmasraya hanya dilakukan di kawasan sungai Nyunyo nagari Tebing Tinggi.Upaya yang telah dilakukan pemerintah adalah reklamasi, ameliorasi, penanaman, pemeliharaan dan pemanfaat lahan.Sedangkan kendala dalam perbaikan lahan bekas tambang adalah minimnya anggaran, sumber daya manusia yang kurang ahli, sarana dan prasarana yang belum lengkap serta kurangnya partisipasi masyarakat.

Kata kunci: peran pemerintah, perbaikan, lahan bekas tambang
\end{abstract}

\section{Abstract}

Pollution and environmental damage are increasingly prevalent in Indonesia. One form of pollution and environmental damage is ex-mining land. Former mining land is a critical land that is not fertile and must be repaired immediately. Dharmasraya Regency has a critical area of 4,144 hectares. The role and efforts of the Dharmasraya Regency government are very much needed to repair ex-mining land. Article 3 letter e Regional Regulation of the Dharmasraya Regency Number 10 of 2012 concerning the Dharmasraya Regency Regional Spatial Planning (RTRW) for 2011-2031 states that the development of the district's mining potential while maintaining environmental quality. This study aims to determine the efforts and constraints of the Dharmasraya Regency government in repairing damage to ex-mining land. This study uses descriptive qualitative methods. The informant technique uses purposive sampling. Techniques for collecting data on interviews, field observations and documentation studies. Based on the results of the study, the repair of ex-mining land in Dharmasraya Regency was only carried out in the Nyunyo river area of Nagari Tebing Tinggi. The efforts that have been made by the government are reclamation, amelioration, planting, maintenance and utilization of land. Whereas the obstacles in repairing ex-mining land are the lack of budget, less skilled human resources, incomplete facilities and infrastructure and a lack of community participation.

Keywords: the role of the government, improvement, ex-mining land

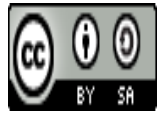

Received: July 24, 2019 


\section{Pendahuluan}

Kualitas lingkungan hidup di Indonesia semakin menurun, Pencemaran dan kerusakan lingkungan hidup terjadi di setiap wilayah Indonesia.(Mubarak, 2014)menjelaskan bahwa pemerintah mengemban tiga fungsi hakiki yaitu pelayanan, pemberdayaan, dan pembangunan. Dari tiga fungsi ini dapat dikelompokkan menjadi dua fungsi yaitu fungsi primer dan sekunder.Salah satu fungsi primer pemerintah adalah mencegah pencemaran dan kerusakan lingkungan hidup.Pencemaran dan kerusakan lingkungan hidup banyak terjadi di hutan dan daerah aliran sungai (DAS).Salah satu bentuk kerusakan dan pencemaran lingkungan hidup adalah lahan kritis.Luas lahan kritis di Indonesia mencapai 14 juta hektar.Lahan kritis merupakan lahan yang minim unsur hara,rawan erosi dan tercemar logam berat yang membuat lahan tidak produktif.Lahan kritis bisa sebabkan karena kegiatan pertambangan yang disebut lahan bekas tambang.Perbaikan lahan kritis harus segera dilakukan agar lahan produktif kembali dan dapat dimanfaatkan.Menurut pasal 28h ayat 1 undang-undang dasar 1945 dijelaskan bahwa setiap orang berhak hidup sejahtera lahir dan batin, bertempat tinggal, dan mendapatkan lingkungan hidup yang baik dan sehat serta berhak memperoleh pelayanan kesehatan. Pada pasal 13 ayat 3 undang-undang nomor 32 tahun 2009 tentang Perlindungan dan Pengelolaan Lingkungan Hidup dijelaskan bahwa pengendalian pencemaran dan/atau kerusakan lingkungan hidup sebagaimana dimaksud pada ayat 1 dilaksanakan oleh pemerintah, pemerintah daerah, dan penanggung jawab usaha dan/atau kegiatan sesuai dengan kewenangan, peran dan tanggung jawab masing-masing. Permasalahan pencemaran dan kerusakan lingkungan hidup menjadi tanggung jawab bersama antara pemerintah dan masyarakat. Dharmasraya merupakan Kabupaten yang terletak di perbatasan Provinsi Sumatera Barat dan Jambi.Sumber penghidupan masyarakat Kabupaten Dharmasraya mayoritas di sektor petanian dan perkebunan.Selain petanian dan perkebun, sektor pertambangan juga memiliki potensi yang besar di Kabupaten Dharmasraya. Pertambangan yang ada seperti tambang emas dan batu bara.Pencemaran dan kerusakan lingkungan tidak sejalan dengan hasil yang ditimbulkan dari sektor pertambangan.Dampak yang buruk ditimbulkan dari sektor pertambangan apabila tidak dikelola dengan baik.Pertambangan yang banyak di Kabupaten Dharmasraya adalah pertambangan emas rakyat tanpa izin (PETI).Pertambangan emas rakyat tanpa izin (PETI) tersebar hampir di seluruh daerah Kabupaten Dharmasraya.Hanya kecamatan Sungai Rumbai yang tidak mempunyai lahan bekas tambang apabila dilihat dari luas dan persebaran lahan kritis di Kabupaten Dharmasraya.Luas dan persebaran lahan kritis di Kabupaten Dharmasraya dalam dilihat pada Gambar 1 berikut ini.

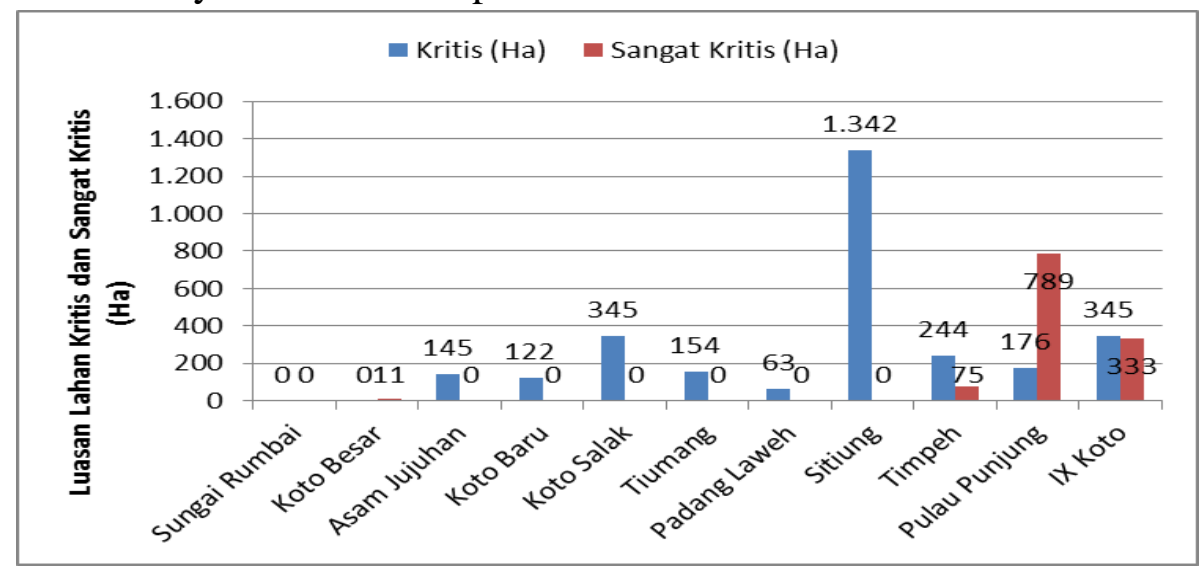

Gambar 1. Luas dan Persebaran Lahan Kritis di Kabupaten Dharmasraya

Jurnal Perspektif: Jurnal Kajian Sosiologi dan Pendidikan Vol. 2, No. 3, Th. 2019 


\section{Sumber: Dinas Lingkungan Hidup Kabupaten Dharmasraya}

Lahan bekas tambang merupakan salah satu bentuk lahan kritis yang banyak di Kabupaten Dharmasraya.Menurut (Wiwik, Ekyastuti dan Dwi Astiani, 2018) lahan tailing bekas tambang emas merupakan lahan kritis dengan berbagai kekurangan yaitu: miskin unsur hara, tidak ada top soil dan bahan organik, struktur tanahnya didominasi oleh fraksi pasir, rawan erosi dan tercemar logam berat merkuri. Kekurangan lahan tersebut menjadi kendala bagi perumbuhan tanaman dan kehidupan di sekitarnya.Oleh karena itu, lahan tailing bekas tambang emas rakyat perlu segera direklamasi.Salah satu rangkaian kegiatan reklamasi lahan bekas tambang emas adalah revegetasi.Lokasi lahan bekas tambang akibat pertambangan emas rakyat tanpa izin (PETI) terdapat di Kawasan Sungai Nyunyo Nagari Tebing Tinggi, Kawasan sungai Asam, sungai Palangko, sungai Samiluan, dan sungai Piruko di nagari Sikabau. Kawasan rawa Jengkol kecamatan Pulau Punjung, Kawasan bukit Gading dan kawasan Aur Jaya di Kecamatan Koto Baru, serta kawasan sungai Rotan di kecamatan Sitiung. Khusus di Kawasan sungai Nyunyo nagari Tebing Tinggi memiliki lahan bekas tambang seluas 300 hektar dan Kawasan sungai Asam, sungai Palangko, sungai Samiluan, dan sungai Piruko di nagari Sikabau memiliki lahan bekas tambang berjumlah 50 hektar.

Pencemarandan kerusakan lingkungan hidup yang terjadi akibat pertambangan emas rakyat tanpa izin (PETI) seperti terganggunya ekosistem alami, kerusakan hutan, pencemaran air sungai yang berdampak pada hilangnya sumber air bersih, terbentuknya kolam-kolam bekas tambang yang membahayakan bagi makhluk hidup, serta tingginya kandungan merkuri yang membuat lahan menjadi kritis dan semakin tidak produktif bahkan tidak dapat dimanfaatkan. Kerusakankerusakan yang telah terjadi apabila tidak segera diperbaiki maka akan menimbulkan permasalahan-permasalahan baru seperti hilangnya mata pencarian masyarakat, longsor, banjir bandang, krisis air bersih dan wabah penyakit. Bentuk kerusakan lahan bekas tambang di Kabupaten Dharmasraya dapat dilihat pada gambar 2 berikut ini.

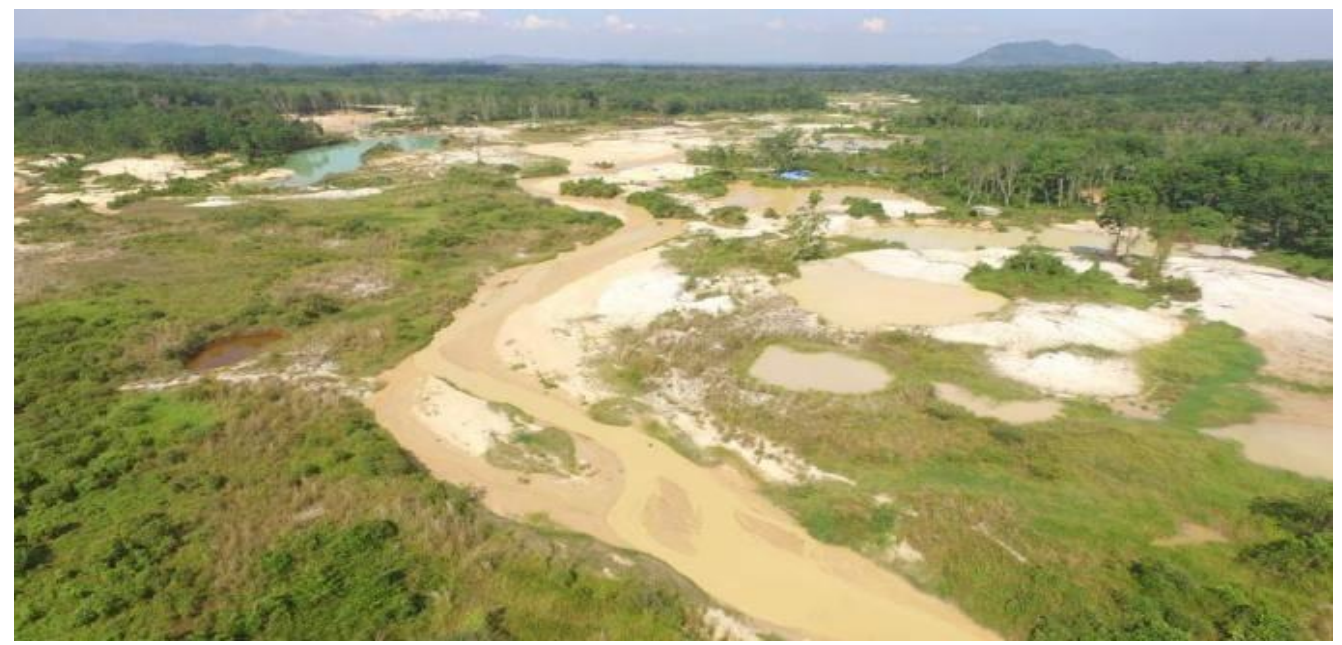

Gambar 2. Kerusakan Lahan Bekas Tambang di Kabupaten Dharmasraya Sumber: Dinas Lingkungan Hidup Kabupaten Dharmasraya

Pasal 3 huruf e Peraturan Daerah Kabupaten Dharmasraya Nomor 10 Tahun 2012 Tentang Rencana Tata Ruang Wilayah (RTRW) Kabupaten Dharmasraya Tahun 2011-2031 menyebutkan bahwa pengembangan potensi pertambangan Kabupaten dengan tetap mempertahankan kualitas lingkungan. Sejalan dengan itu, Bupati Kabupaten Dharmasraya Sutan Riska Tuanku Kerajaan 
mempunyai misi memelihara kualitas lingkungan hidup Kabupaten Dharmasraya untuk mendukung pembangunan yang berkelanjutan.Mempertegas visi Bupati, Dinas Lingkungan Hidup Kabupaten Dharmasraya memiliki tujuan penghijauan lahan kritis, pelestarian keanekaragaman hayati dan pengendalian pencemaran lingkungan (rencana pembangunan jangka menengah daerah Kabupaten Dharmasraya 2016-2021).

Peran pemerintah Kabupaten Dharmasraya melalui Dinas Lingkungan Hidup sangat diperlukan untuk memperbaiki kerusakan lahan akibat pertambangan emas rakyat tanpa izin (PETI). Berdasarkan Undang-Undang 23 Tahun 2014 Tentang Pemerintahan Daerah lampiran k Dinas Lingkungan Hidup terbagi atas sebelas sub bidang. Salah satu sub bidangnya adalah pengendalian pencemaran dan/atau kerusakan lingkungan hidup, pencegahan, penanggulangan dan pemulihan pencemaran dan atau/atau kerusakan lingkungan hidup daerah kabupaten/kota. Sub bidang ini yang bertugas untuk memperbaiki kerusakan lahan bekas tambang. Program Dinas Lingkungan Hidup Kabupaten Dharmasraya yang berhubungan dengan lahan bekas tambang adalah konservasi sumber daya air dan pengendalian kerusakan sumber-sumber air, pengendalian kerusakan hutan dan lahan, rehabilitasi hutan dan lahan, peningkatan peran serta masyarakat dalam rehabilitasi dan pemulihan cadangan sumber daya alam.

Menurut (Notohadirprawiro, 2006) pemugaran lahan yang terkena dampak berat dari pertambangan dapat dilakukan dengan 2 (dua) upaya:pertama, reklamasi, yaitu pengembalian dayaguna lahan yang telah hilang, atau membuat lahan yang tidak berdayaguna menjadi berdayaguna. Tindakan ditujukan menghilangkan kerusakan dan kedua, ameliorasi, yaitu meningkatkan daya guna lahan. Tindakan ditujukan memperbaiki mutu lahan setelah kerusakan berhasil dihilangkan.

Upaya selanjutnya (Misbakhul Munir dan RR Diah Nugraheni Setyowati, 2017)menyebutkan bahwa proses revegetasi dalam melakukan reklamasi untuk lahan bekas tambang dibagi menjadi 3 tahap: pertama, persiapan lahan, dalam persiapan lahan terdapat tiga hal yang dilakukan yaitu pengolahan tanah, pembuatan drainase, dan perbaikan tanah, kedua pelaksanaan penanaman, idealnya pelaksanaan penanaman pohon dilakukan di awal atau selama musim penghujan dan ketiga pemeliharaan, untuk mempermudah pemeliharaan, pengawasan, dan evaluasi, pemasangan papan informasi di lokasi tanam harus dilakukan.

(Misbakhul Munir dan RR Diah Nugraheni Setyowati, 2017)juga menjelaskan bahwa Faktor penghambat pelaksanaan reklamasi pada lahan bekas tambang yaitu, pertama, tidak adanya partisipasi dari masyarakat. Partisipasi mayarakat dalam kegiatan reklamasi menjadi hal yang sangat penting, dikarekan dengan partisipasi tersebut kegiatan reklamasi diharapkan berhasil. Partisipasi masyarakat yang diharapkan berupa tidak adanya masyarakat yang melakukan penambangan di sekitar lokasi reklamasi selama proses reklamasi berlangsung dan kedua, Kesalahan teknologi dalam melakukan reklamasi. Pemilihan teknologi yang tepat guna perlu dilakukan sebelum reklamasi. Agar reklamasi berhasil dilaksanakan.

\section{Metode Penelitian}

Penelitian ini menggunakan jenis kualitatif dengan metode deskriptif. Menurut (Moleong, 2005)Penelitian kualitatif adalah suatu proses penelitian yang menghasilkan data deskriptif berupa kata-kata tertulis atau lisan dari orang-orang dan perilaku yang dapat diamati.Penelitian ini dilaksanakan di Dinas Lingkungan Hidup Kabupaten Dharmasraya, kantor wali nagari Tebing Tinggi dan kantor wali nagari Sikabau yang terletak di Kecamatan Pulau Punjung Kabupaten Dharmasraya Provinsi Sumatera Barat. Menurut (Sugiyono, 2011)Teknik yang digunakan adalah 
teknik purposive sampling, yaitu Pemilihan sumber data dari orang yang diwawancarai dengan pertimbangan dan tujuan tertentu.

Informan dari penelitian ini merupakan pihak-pihak yang dianggap paling memahami tentang informasi yang akan peneliti butuhkan mengenai peran pemerintah Kabupaten Dharmasraya dalam memperbaiki kerusakan lahan bekas tambang. Informan peneliti adalahKepala seksi pengendalian pencemaran dan kerusakan lingkungan hidup Dinas Lingkungan Hidup Kabupeten Dharmasraya, wali nagari Tebing Tinggi, wali nagari Sikabau, masyarakat yang pernah memiliki lahan bekas tambang dan masyarakat yang terdampak kerusakan lahan bekas tambang seperti masyarakat yang bertempat tinggai di dekat sungai. Keabsahan data menggunakan teknik triangulasi sumber, dan di analisis dengan reduksi data, penyajian data serta penarikan kesimpulan.Data yang digunakan berupa adalah data primer yang bersumber dari hasil wawancara dan observasi serta data sekunder yang diperoleh dari dokumentasi lapangan, peraturan perundang-undangan dan data lainnya yang berkaitan dengan peran pemerintah Kabupaten Dharmasraya dalam memperbaiki kerusakan lahan bekas tambang.

\section{Hasil dan Pembahasan}

\section{Upaya dalam perbaikan lahan bekas tambang}

Pemerintah Kabupaten Dharmasraya melalui Dinas Lingkungan Hidup telah melakukan upaya-upaya untuk memperbaiki kerusakan lahan bekas tambang akibat pertambangan emas rakyat tanpa izin (PETI). Perbaikan yang telah dilakukan hanya di kawasan sungai Nyunyo nagari Tebing Tinggi, sedangkan kawasan lain di Kabupaten Dharmasraya belum dilaksanakan perbaikan. Upaya-upaya yang telah dilakukan adalah reklamasi, ameliorasi, penanaman tanaman dan penghijauan, pemeliharaan serta pemanfaatan lahan.Lebih jelasnya dapat dilihat pada uraian berikut.

\section{Reklamasi}

Reklamasi lahan bekas tambang emas rakyat tanpa izin (PETI) yang ditelah dilakukan oleh pemerintah Kabupaten Dharmasraya melalui Dinas Lingkungan Hidup bekerja sama dengan Kementrian Lingkungan Hidup dan Kehutanan (KLHK), penyedia jasa kontruksi dan pemerintahan nagari serta masyarakat. Lokasi lahan bekas tambang yang telah dilaksanakan reklamasi adalah di kawasan sungai Nyunyo nagari Tebing Tinggi Kecamatan Pulau Punjung. Pada tahun 2018 Luas lahan yang direklamasi 3,8 hektar dan yang akan direklamasi tahun 2019 ini seluas 4,5 hektar. Total luas lahan yang direklamasi adalah 8,3 hektar. Sedangkan luas lahan bekas tambang emas rakyat tanpa izin (PETI) di kawasana sungai Nyunyo 300 hektar.Lahan bekas tambang emas rakyat tanpa izin (PETI) di daerah lain yang tersebar luas di Kabupaten Dharmasraya belum dilakukan reklamasi atau upaya lainnya. Reklamasi di kawasan sungai Nyunyo adalah kegiatan reklamasi yang pertama kali dilakukan oleh pemerintah Kabupaten Dharmasraya.

\section{Ameliorasi}

Setelah reklamasi dilakukan, tahap selanjutnya adalah ameliorasi. Ameliorasi adalah upaya yang dilakukan untuk meningkatkan daya guna lahan.Tindakan ini dilakukan untuk memperbaiki mutu lahan setelah kerusakan berhasil dihilangkan. Kegiatan ameliorasi pada lahan bekas tambang emas rakyat tanpa izin (PETI) berupa menganalisis keadaan lahan, kandungan unsur hara yang ada pada lahan, melakukan cek laboratorium pada air dikawasan lahan bekas tambang, 
tanaman yang cocok untuk lahan, dan untuk apa pemanfaatan lahan bekas tambang selanjutnya. Ameliorasi dilakukan bekerja sama dengan ahli lingkungan, tim labor dan akademisi.

\section{Penanaman tanaman dan penghijauan}

Tahan selanjutnya adalah pelaksanaan penanaman. Setelah lahan siap untuk ditanami maka sesuai dengan rencana, pada lahan bekas tambang emas rakyat tanpa izin (PETI) akan ditaman bermacam-macam jenis bambu. Pohon bambu dipilih karena sesuai dengan kriteria lahan. Kurang lebih ada 9.702 pohon bambu yang akan ditamani diatas lahan seluas 8,3 hektar. Sedangkan yang sudah ditamani sebanyak 1000 pohon diatas lahan seluas 3,8 hektar. Pohon bambu dipilih karena cocok dengan karakteristik lahan bekas tambang dan banyak memiliki manfaat bagi masyarakat sekitar.

\section{Pemeliharaan tanaman}

Pohon bambu yang sudah ditanam harus pelihara dan (Mubarak, 2014) dirawat dengan baik agar tetap hidup dan bisa tumbuh maksimal. Bentuk pemeliharaan pohon bambu pada area lahan bekas tambang emas rakyat tanpa izin (PETI) di kawasan sungai Nyunyo nagari Tebing Tinggi adalah dengan mempersiapkan keran-keran air di selah-selah pohon bambu untuk penyiraman. Bentuk pemeliharaan lainnya adalah dengan mengganti dan menanami kembali pohon bambu yang mati.Pemeliharaan harus dilakukan secara berkala.

\section{Pemanfataan lahan}

Lahan bekas tambang emas rakyat tanpa izin (PETI) di kawasan sungai Nyunyo yang telah direklamasi dan ditamani pohon bambu akan dimanfaatkan menjadi tempat wisata dengan konsep taman bambu yang diberi nama Dharmasraya Edu Eco Green. Tempat yang diberi nama Dharmasraya Edu Eco Greenini akan dijadikan tempat penelitian berbagai jenis bambu dan tempat wisata. Fasilitas pendukung sebagai tempat wisata telah disediakan seperti: gerbang masuk, jalan beton di dalam kawasan wisata, wc, mushallah dan keran air. Sedangkan fasilitas yang akan dibuat adalah jembatan yang menghubungkan lokasi reklamasi pertama dan lokasi reklamasi kedua. Dharmasraya Edu Eco Green akan dikelola oleh pemerintah nagari Tebing Tinggi menjadi badan usaha milik nagari (BUMNAG) dibawah pengawasan pemerintah Kabupaten.Beralihnya lahan bekas tambang emas menjadi tempat wisata diharapkan dapat meningkatkan perekonomian masyarakat setempat dan menjadi percontohan bagi daerah lain untuk mengelola lahan bekas tambang.

\section{Kendala dalam perbaikan lahan bekas tambang}

Kendala-kendala yang ditemui oleh pemerintah kabupaten Dharmasraya melalui Dinas Lingkungan Hidup dalam memperbaiki kerusakan lahan bekas tambangadalah minimnya anggaran, sumber daya manusia yang kurang ahli, sarana dan prasarana kurang lengkap serta minimnya partisipasi masyarakat. Lebih jelasnya dapat dipahami mengenai kendala pada uraian berikut ini.

\section{Anggaran}

Reklamasi lahan bekas tambang di Kabupaten Dharmasraya terkendala karena anggaran yang minim. Sangat dibutuhkan anggaran yang besar untuk reklamasi lahan bekas tambang yang luasnya mencapai ribuan hektar. Sebagai perbandingannya, untuk reklamasi lahan seluas 8,3 hektar membutuhkan anggaran 2,8 miliyar. Sebagai perbandingan pada tahun 2018 anggaran Dinas Lingkungan Hidup untuk program pengendalian pencemaran dan perusakan lingkungan hidup hanya Rp 478.993.850,-. Saat ini reklamasi lahan bekas tambang emas hanya dilakukan di 
kawasan sungai Nyunyo kenagarian Tebing Tinggi dengan sumber anggaran dari Kementrian Lingkungan Hidup dan Kehutanan (KLHK) dan Dinas Lingkungan Hidup (DLH). Sementara di daerah lain yang mempunyai lahan bekas tambang belum dilakukan reklamasi atau upaya lainnya.

\section{Sumber daya manusia}

Sumber daya manusia yang kurang ahli dapat dilihat dari pekerjaan reklamasi yang tidak dilakukan langsung oleh Dinas Lingkungan Hidup Kabupaten Dharmasraya. Reklamasi tahap pertama pada tahun 2018 dikerjakan oleh CV. Tirta Planning Engineering Consultant dan reklamasi tahap kedua pada tahun 2019 dikerjakan oleh CV. Zah-va. Sedangkan Dinas Lingkungan Hidup sebagai penyedia anggaran dan pembuatan izin.

Jumlah pegawai yang sedikit di bidang pengendalian, pemeliharaan dan peningkatan kapasitas lingkungan hidup pada Dinas Lingkungan Hidup Kabupaten Dharmasraya.Pegawai di bidang ini hanya berjumlah 5 orang yang terdiri dari 1 kepala bidang, 2 kepala seksi, dan 2 orang staf. Dari 5 orang pegawai yang ada dibidang pengendalian, pemeliharaan dan peningkatan kapasitas lingkungan hidup pada Dinas Lingkungan Hidup Kabupaten Dharmasraya hanya 1 orang yang mempunyai kualifikasi lingkungan. Selainnya mempunyai kualifikasi sosial, biologi, analis kesehatan dan keuangan perbankan.Bidang pengendalian, pemeliharaan dan peningkatan kapasitas lingkungan hidup merupakan bidang yang bertugas untuk memperbaiki kerusakan lahan bekas tambang atau lahan akses terbuka (LAT).

\section{Sarana dan prasarana}

Kegiatan reklamasi lahan bekas tambang emas tanpa izin (PETI) yang dilakukan oleh pemerintah kabupaten Dharmasyara melalui Dinas Lingkungan Hidup terkendala karena minimnya sarana dan prasarana yang dimiliki. Sarana dan prasaran untuk reklamasi diantaranya escavator, bulldozer, truk, dan sebagainya. Kurangnya sarana dan prasarana yang dimiliki membuat Dinas Lingkungan Hidup bekerja sama dengan jasa penyedia konstruksi dalam pelaksanaan reklamasi lahan bekas tambang.

\section{Partisispasi masyarakat}

Kegiatan reklamasi lahan bekas tambang sangat bergantung pada partisipasi masyarakat, khususnya masyarakat yang tinggal di sekitar lokasi reklamasi. Pada pelaksanaan reklamasi lahan bekas tambang emas rakyat tanpa izin (PETI) di kawasan sungai Nyunyo nagari Tebing Tinggi masih ada dari masyarakat yang tidak mendukung. Masyarakat yang tidak mendukung misalnya masyarakat yang masih melakukan kegiatan pertambangan emas tanpa izin (PETI) sedangkan pemerintah Kabupaten sedang melaksanakan reklamasi lahan bekas tambang. Kegiatan pertambangan yang masih dilakukan oleh masyarakat akan mengganggu reklamasi yang sedang dilaksanakan.

\section{Kesimpulan}

Pemerintah Kabupaten Dharmasraya melalui Dinas Lingkungan Hidup telah melakukan upaya-upaya untuk memperbaiki kerusakan lahan bekas tambang. Namun perbaikan lahan bekas tambang masih dilakukan di kawasan yang sama dengan luas lahan yang masih sedikit. Perencanaan perbaikan lahan bekas tambang dimulai sejak tahun 2016 dengan pengajuan proposal kepada Kementerian Lingkungan Hidup dan Kehutanan (KLHK). Pada tahun 2017 tinjauan lapangan dilakukan dan pada tahun 2018 perbaikan tahap pertama dilaksanakan. Pada tahun 2019 perbaikan tahap kedua dilaksanakan dilokasi yang sama. 
Perbaikan lahan bekas tambang yang dilakukan oleh Pemerintah Kabupaten Dharmasraya melalui Dinas Lingkunganbekerja dengan Kementerian Lingkungan Hidup dan Kehutanan (KLHK), penyedia jasa konstruksi dan pemerintahan nagari. Perbaikan lahan bekas tambang telah dilakukan di kawasan sungai Nyunyo nagari Tebing Tinggi dengan luas lahan yang diperbaiki 8,3 hektar dari 300 lahan yang rusak. Sedangkan di kawasan lain belum ada perbaikan lahan bekas tambang. Adapun upaya yang telah dilakukan adalah reklamasi, ameliorasi, penanaman dan penghijauan, pemeliharaan dan pemanfaatan lahan.Sedangkan kendala-kendala yang ditemui dalam melaksanakan upaya adalah minimnya anggaran, sumber daya manusia yang minim, sarana dan prasana belum lengkap, serta kurangnya partisipasi masyarakat.

\section{Daftar Pustaka}

Misbakhul Munir dan RR Diah Nugraheni Setyowati. (2017). Kajian Reklamasi lahan Pasca Tambang di Jambi, Bangka dan Kalimantan Selatan. Jurnal Klorofil Vol. 1 No. 1, 11-16.

Moleong, L. J. (2005). Metode Penelitian Kualitatif. Bandung: PT Remaja Rosdakarya.

Mubarak, A. (2014). Peran Ormas dalam Menjalankan Fungsi Pemerintah Bidang Pemberdayaan. Seminar nasional UT2014, universitas terbuka convention center (UTCC), Hal 1-10.

Notohadirprawiro, T. (2006). Pengelolaan Lahan dan Lingkungan Pasca Penambangan. Hal 112.

Peraturan Daerah Kabupaten Dharmasraya Nomor 10 Tahun 2012 Tentang Rencana Tata Ruang Wilayah (RTRW) Kabupaten Dharmasraya Tahun 2011-2031

Sugiyono. (2011). Metode Penelitian Administrasi Metode R\&B. Bandung: Alfabeta.

Undang-Undang Nomor 32 Tahun 2009 Tentang Perlindungan dan Pengelolaan Lingkungan Hidup

Undang-Undang Nomor 23 Tahun 2014 tentang Pemerintahan Daerah

Undang-Undang Dasar 1945

Wiwik, Ekyastuti dan Dwi Astiani. (2018). Produksi Kompos untuk Mendukung Keberhasilan Reklamasi Lahan Tailing Bekas Tambang Emas Rakyat. Jurnal Penganbdian dan Pemberdayaan Masyarakat, Hal 1-7. 